\title{
Emergency Thoracotomy- Isolated Internal Thoracic Artery Injury
}

Islam $\mathbf{S}^{*}$, Shah $\mathbf{J}$ and Narayn Singh V

Department of Clinical Surgical Sciences, University of the West Indies, St Augustine, Trinidad and Tobago

\begin{abstract}
Aim: A tension haemothorax is an uncommon injury after penetrating chest trauma. Presentation of a Case: We present a case in which a 55 year old man sustained multiple thoracic stab wounds. He had emergency right antero-lateral thoracotomy and laparotomy. A massive haemothorax secondary to complete disruption of right internal mammary artery and a laceration to middle lobe of right lung was noticed. Conclusion: Penetrating thoracic injury with isolated internal mammary injury is a very rare cause of massive haemothorax and associated with high mortality. Emergent thoracotomy can be life-saving for these patients. Introduction: Anterior thoracic penetrating injuries may result in life-threatening complications. One of these is massive tension haemothorax with pericardial tamponade as a result of stab wounds to the internal mammary artery.
\end{abstract}

\section{Case Report}

A 55 year old chronic alcoholic, male presented to the San Fernando General Hospital of Trinidad and Tobago after sustaining multiple [1] stab wounds (SW) to the chest \&upper abdomen [2]. He was in hypovoluemic shock with a blood pressure of $70 / 30 \mathrm{~mm} \mathrm{Hg}$ and pulse rate of 140 beats per minute. Multiple [3] stab wounds were noted, in his right anterior chest wall medial to mid-clavicular line and one in left parasternal area at $4^{\text {th }}$ ICS just cutting through the cartilage but not penetrating into the chest and two stab wound just below the tip of xyphoid process of sternum of which one is penetrating into abdomen (Figure 1).

A right chest was placed and immediately drained 1200mls of blood FAST \& CXR were done moment after arrival in ED. The FAST revealed no blood in pericardial sac, however minimal free fluid was noted in the abdomen. The CXR later on showed complete opacification of entire right lung (Figure 2).

Right chest tube continue to drain blood with further drop in blood pressure of $40 / 25 \mathrm{~mm} \mathrm{Hg}$, immediately take to OR within 1520 minutes of arrival in ED. However, en-route to OR, patient had a sudden cardiac arrest which was successfully resuscitated with a minutes of CRP and proceeds immediately to the OR. The pleural cavity was entered through a right antero-lateral thoracotomy incision in the $4^{\text {th }}$ intercostal space under aseptic condition (Figure 3 ).

Right hemothorax was confirmed with laceration of right internal thoracic artery with active bleeding and small $1 \mathrm{x} 1 \mathrm{~cm}$ laceration to

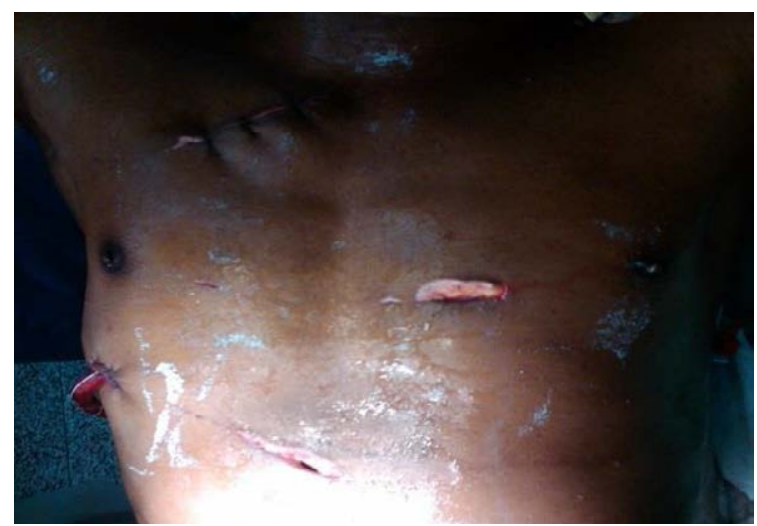

Figure 1: Sites of Stab wound on chest and wound. middle lobe of right lung. The pericardium was felt empty with no evidence of blood in the pericardial cavity. The bleeding vessel was controlled initially by digital pressure and then ligated proximally and distally. Simple repair of lung laceration was done (Figure 4).

A midline laparotomy revealed a $3 \mathrm{~cm}$ laceration to left lobe of live with no active bleeding and there were minimal blood in the peritoneal cavity with no other visceral injury. The chest and abdomen was closed respectively leaving a 32 size chest tube in right pleural cavity. The estimated blood loss was approximately 6 litres. Patient received multiple transfusions of blood and blood products. Patient was managed in ICU for 2 day and subsequently transferred to the surgical ward where he developed delirium tremens secondary to with drawl of alcohol. Patient recovered completely well from the incident and discharged home on $8^{\text {th }}$ post-operative day.

\section{Discussion}

Injury to Internal mammary artery is infrequently reported in literature. It can be a result of penetrating or blunt trauma, both of rare in occurrence but still with serious consequences $[4,5]$. Others have described internal mammary injury that had occurred from central line insertion [5]. There are only five cases of isolated IMA injury patient with successful recovery after emergency thoracotomy has been reported in the literature.

Among the 4 penetrating injuries two [6,7] were hemo-dynamically unstable \& the next 2 [8] were hemodynamically stable. Only one patient had early [7] and next two patients had late pericardial tamponade $[9,10]$ and last one [6] presented with early external pericardial tamponade. Of the 4 penetrating injuries patients only 2 had early [6,7] and 1 had delayed massive hemothorax [8] however,

*Corresponding author: Shariful Islam, Department of Clinical Surgical Sciences, University of the West Indies, St Augustine, Trinidad and Tobago, Tel: 868-797-4951; Fax: 868-797-4951; E-mail: shar islam7@hotmail.com

Received June 20, 2014 ; Accepted June 27, 2014; Published September 20, 2014

Citation: Islam S, Shah J, Singh VN. Emergency Thoracotomy- Isolated Interna Thoracic Artery Injury. Journal of Surgery [Jurnalul de chirurgie] 2014; 10(2): 187-189 DOI: 10.7438/1584-9341-10-2-17

Copyright: ( 2014 Islam S, et al. This is an open-access article distributed unde the terms of the Creative Commons Attribution License, which permits unrestricted use, distribution, and reproduction in any medium, provided the original author and source are credited. 


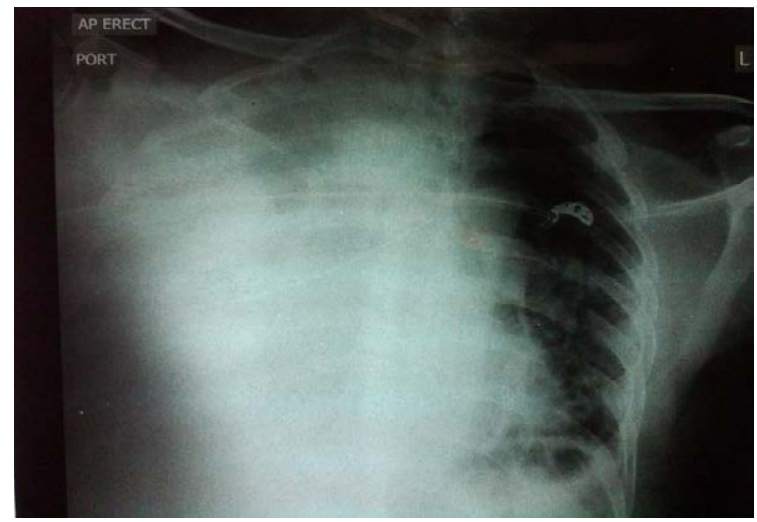

Figure 2: C x R AP showing complete white out of right hemi-thorax.

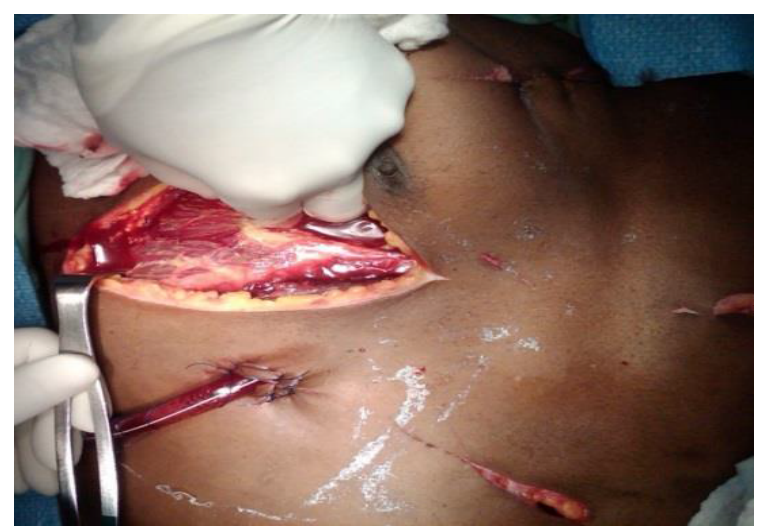

Figure 3: Right antero-lateral thoracotomy incision.
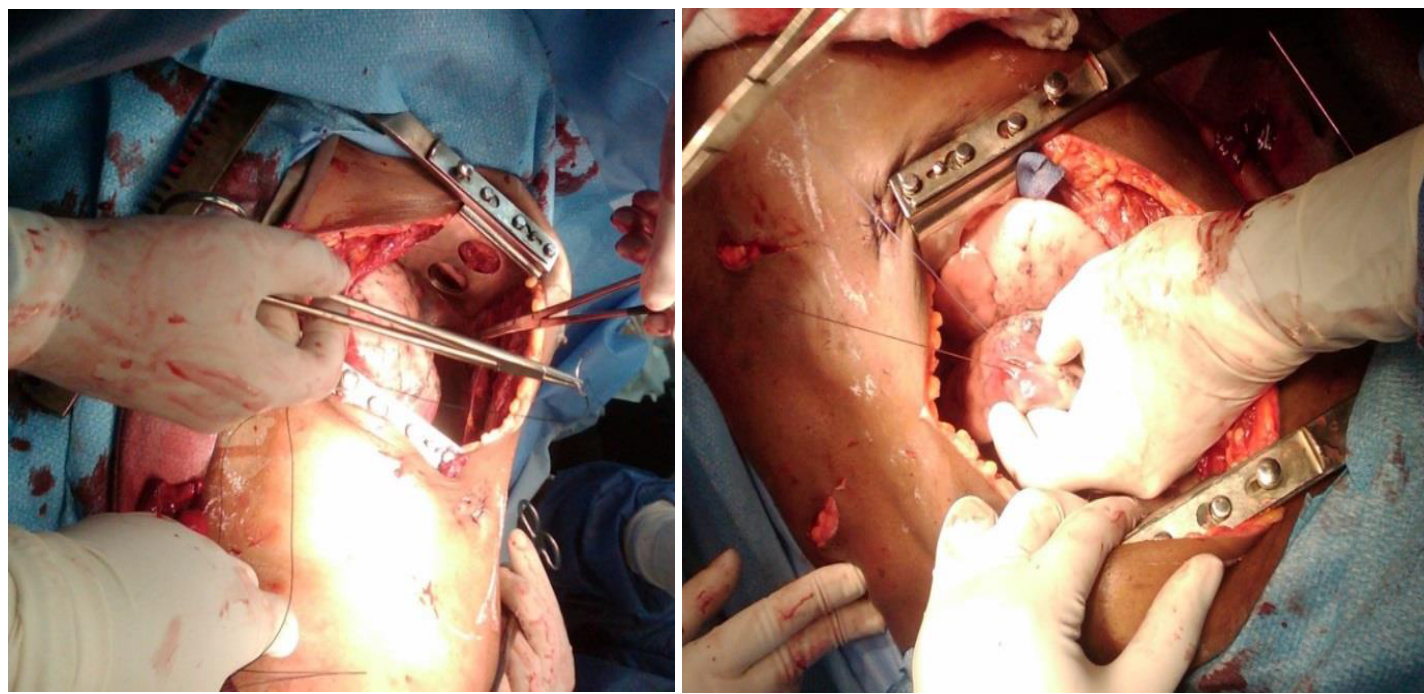

Figure 4: Chest opened \& Right IMA is clamped \& suture ligated, repair of lung laceration.

Table I: Summary of the Review of literature of internal mammary artery injuries

\begin{tabular}{|l|c|c|c|c|c|}
\hline \multicolumn{1}{|c|}{ Study } & Mechanism of injury & Hemodynamic & Pericardial Tamponade & Massive Hemothorax & Surgery \\
\hline Curley et al. (1987)[12] & Penetrating & Unstable & Early & Early \\
\hline Vinces (2005) [6] & Penetrating & Stable & Delayed & Delayed \\
\hline Holt et al. (2005) [11] & Penetrating & Stable & Delayed & Tho & Alive \\
\hline Irgau et al. (1995) [8] & Blunt & Stable & Delayed external & Sternotomy \\
\hline Hassani (2012) [1] & Penetrating & Unstable & Early external & Alive \\
\hline Current case & Penetrating & Unstable & Early external & Early & Tlive \\
\hline
\end{tabular}

the next one had no massive hemothorax [9] Two of the penetrating injuries patients underwent median sternotomy [7,9] and the next two underwent anterolateral thoracotomy $[6,8]$. The lone blunt injury patient presented with delayed peri-cardial tamponade and was hemodynamically stable with no massive hemothorax and underwent median sternotomy [10] . Only one case has documented pre hospital arrest [6]. Our patient presented in a hemo-dynamically unstable condition with multiple stab wounds in the chest with massive tension hemothorax with early external cardiac tamponade. Our patient had a witnessed cardic arrest just moment before OR, was successfully resuscitated and underwent emergency thoracotomy with ligation IMA with an excellent full recovery (Table I).

As noted from the above, the presentation of internal-mammary injury varies from relatively stable patient that can be studied in a timely manner to identify the source of hemothorax, to a delayed presentation of massive hemothorax that mandate thoracotomy [11,12]. The treatment depends on patient hemodynamic status. With simultaneous resuscitation with placement of a chest tube to immediately release the tension hemothorax is the first line of intervention in patient who has signs of life in ED. However, once cardiac arrest is witnessed 5 minutes prior to Ed or in ED ER thoracotomy should the performed, if there is a surgeon in the institution rendering the care. The injured internal mammary may be treated based on the clinical presentation. If patient is hemo-dynamically stable and facilities are available the angioembolization of the injured vessels are recommended.

\section{Conclusion}

Penetrating thoracic injury with isolated IMA injury is a very rare cause of massive haemothorax and associated with high mortality. Appropriate and Quick selections of the ideal patients for ED or OR thoracotomy are paramount important for successful outcomes. 


\section{Conflict of interest}

The authors have no conflict of interest to report.

\section{References}

1. CJ Whigham, RG Fisher, CJ Goodman, CA Dodds, and CC Trinh (2002) "Traumatic injury of the internal mammary artery: embolization versus surgical and non-operative management," Emergency Radiology 9: 201-207.

2. Khoynezhad A, Barrett L, Hayn E, Shaftan GW (2004) Total mediastinal traverse with isolated internal mammary artery transection. J Card Surg 19: 136-138.

3. CC Cothren, EE Moore (2006) "Emergency department thoracotomy for the critically injured patient: objectives, indications, and outcomes," World Journal of Emergency Surgery, vol 1: article 4.

4. S. Kawamura, H Nishimaki, M Takigawa (2006) "Internal mammary artery injury after blunt chest trauma treated with trans-catheter arterial embolization," Journal of Trauma, vol. 61: 1536-1539.

5. Mazeh H, Alaiyan B, Vald O, Mizrahi I, Klimov A, et al. (2010) Internal mammary artery injury during central venous catheter insertion for TPN: rare but fatal. Nutrition 26: 849-851.

6. Ammar A Hassani, YA Rahman, A Kanbar, A El-Menyar, A Al-Aieb, M Asim , and R Latifi (2012) Left Internal Mammary Artery Injury Requiring Resuscitative
Thoracotomy : A Case Presentation and Review of the Literature, Case Reports in Surgery: Article ID 459841

7. FY Vinces (2005) "Delayed hemothorax and pericardial tamponade secondary to stab wounds to the internal mammary artery," European Journal of Trauma 31: $274-277$.

8. P Holt, K Stone-Tolcher, I Franklin (2005) "An unusual cause of tamponade," Scandinavian Journal of Trauma, Resuscitation and Emergency Medicine, vol. 13: $236-238$.

9. I. Irgau, GJ Fulda, D Hailstone, and GH Tink off (1995) "Internal mammary artery injury, anterior mediastinal hematoma, and cardiac compromise after blunt chest trauma," Journal of Trauma, vol. 39: 1018-1021.

10. Ritter DC, Chang FC (1995) Delayed hemothorax resulting from stab wounds to the internal mammary artery. J Trauma 39: 586-589.

11. OY Kwon, SP Chung, IS Yoo, CJ Song, IB Kim, and SW Kim (2005) "Delayed presentation of internal mammary artery rupture after blunt chest trauma: characteristics CT and plain x ray findings," Emergency Medicine Journal, vol 22: 664-665.

12. K Gumm, R Judson, M Walsh, P Antippa, B Thomson, et al. (2011) The Royal Melbourne Hospital ,Emergency Department Thoracotomy Guideline Developed by: Advisory Committee on Trauma Created: Version 1.0. 